\title{
The role of an anterior approach in the treatment of ankylosing spondylitis-associated cervical fractures: a systematic review and meta-analysis
}

\author{
Vaidya Govindarajan, BS, Jean-Paul Bryant, MS, Roberto J. Perez-Roman, MD, and \\ Michael Y. Wang, MD
}

Department of Neurological Surgery and The Miami Project to Cure Paralysis, University of Miami Miller School of Medicine, Miami, Florida

\begin{abstract}
OBJECTIVE Cervical fractures in patients with ankylosing spondylitis can have devastating neurological consequences. Currently, several surgical approaches are commonly used to treat these fractures: anterior, posterior, and anteriorposterior. The relative rarity of these fractures has limited the ability of surgeons to objectively determine the merits of each. The authors present an updated systematic review and meta-analysis investigating the utility of anterior surgical approaches relative to posterior and anterior-posterior approaches.

METHODS After a comprehensive literature search of the PubMed, Cochrane, and Embase databases, 7 clinical studies were included in the final qualitative and 6 in the final quantitative analyses. Of these studies, 6 compared anterior approaches with anterior-posterior and posterior approaches, while 1 investigated only an anterior approach. Odds ratios and $95 \%$ confidence intervals were calculated where appropriate.
\end{abstract}

RESULTS A meta-analysis of postoperative neurological improvement revealed no statistically significant differences in gross rates of neurological improvement between anterior and posterior approaches $(\mathrm{OR} 0.40,95 \% \mathrm{Cl} 0.10-1.59 ; p=$ 0.19). However, when analyzing the mean change in neurological function, patients who underwent anterior approaches had a significantly lower mean change in postoperative neurological function relative to patients who underwent posterior approaches (mean difference [MD] $-0.60,95 \% \mathrm{Cl}-0.76$ to $-0.45 ; p<0.00001$ ). An identical trend was seen between anterior and anterior-posterior approaches; there were no statistically significant differences in gross rates of neurological improvement (OR 3.05, 95\% Cl 0.84-11.15; $p=0.09$ ). However, patients who underwent anterior approaches experienced a lower mean change in neurological function relative to anterior-posterior approaches (MD $-0.46,95 \% \mathrm{Cl}$ -0.60 to $-0.32 ; p<0.00001$ ). There were no significant differences in complication rates between anterior approaches, posterior approaches, or anterior-posterior approaches, although complication rates trended lower in patients who underwent anterior approaches.

CONCLUSIONS The results of this review and meta-analysis demonstrated the varying benefits of anterior approaches relative to posterior and anterior-posterior approaches in treatment of cervical fractures associated with ankylosing spondylitis. While reports demonstrated lower degrees of neurological improvement in anterior approaches, they may benefit patients with less-severe injuries if lower complication rates are desired.

https://thejns.org/doi/abs/10.3171/2021.7.FOCUS21333

KEYWORDS ankylosing spondylitis; cervical; anterior approach; fracture; meta-analysis

A NKYLOSING spondylitis (AS) is a seronegative autoimmune disorder characterized by inflammatory back pain and axial skeleton deformities leading to significant morbidity. ${ }^{1} \mathrm{AS}$ is believed to have a multifactorial pathogenesis, with environment, sex, and genetic predisposition impacting susceptibility. It is typically a disease of young men, with a peak onset in the 3rd to 4th decades. ${ }^{2}$ While human leukocyte antigen-B27 (HLA$B 27$ ) remains the primary genetic association, only $5 \%$ of $H L A-B 27$ positive patients ultimately develop AS, further highlighting the multifactorial nature of this disease. ${ }^{3}$

The bony manifestations of AS are believed to be due to progressive osteoproliferation leading to the formation of syndesmophytes. Subsequently, they cause the forma-

ABBREVIATIONS AS = ankylosing spondylitis; $\mathrm{MD}=$ mean difference; NIS = National (Nationwide) Inpatient Sample. ACCOMPANYING EDITORIAL DOI: 10.3171/2021.7.FOCUS21432.

SUBMITTED June 1, 2021. ACCEPTED July 13, 2021.

INCLUDE WHEN CITING DOI: 10.3171/2021.7.FOCUS21333. 
tion of osseous bridges in place of native connective tissue, leading to progressive kyphosis and decreased bone mineral density, making the spine susceptible to fractures even in the setting of minor trauma. ${ }^{4}$ The cervical spine is the most common site for fractures, followed by the thoracic spinal column. ${ }^{5,6}$ Early-stage AS is marked by decreased cervical bone mass, increasing the risk of cervical fracture in AS patients. ${ }^{7}$ Subsequent disease progression leads to spinal fusion, which can result in fractures adjacent to the site of fusion or at the junction of fused and mobile segments. These fractures most commonly occur between $\mathrm{C} 5$ and $\mathrm{C} 7 .^{8-10}$

Cervical fractures may have devastating consequences due to potential spinal cord injury and have the strongest correlation with hospital mortality. ${ }^{11}$ Therefore, immediate diagnosis and treatment is necessary to prevent severe neurological sequelae in this patient population. While most vertebral fractures are detected and subsequently treated, many cervical fractures are often undiagnosed because they occur in the presence of minimal forces. ${ }^{3}$ The rarity of cervical fractures due to AS, coupled with the unique structure of the AS-affected spine, has rendered the creation of formal treatment protocols difficult. ${ }^{12}$ The lack of a standard treatment regimen has created an ongoing debate among practitioners regarding the use of anterior, posterior, or circumferential approaches for fixation in patients with cervical fractures. ${ }^{12}$ Among these approaches, several studies have found that posterior approaches might be preferred over anterior approaches, although a study by Longo et al. found that combined approaches tend to be most commonly used.,13 Thus, a systematic review of the existing literature is necessary to guide the formation of an eventual consensus on treatment of these fractures. Here, we present an updated systematic review and meta-analysis of anterior approaches for fixation of cervical fractures in patients with AS and compare their neurological improvement and complication rates with those of posterior and anterior-posterior approaches.

\section{Methods}

\section{Inclusion and Exclusion Criteria}

Studies evaluating surgical treatment of cervical fractures and their clinical outcomes in patients with AS were included. The exclusion criteria were 1) nonhuman studies, 2) cohorts that did not incorporate surgical management, 3) studies that did not specifically evaluate anterior approaches, 4) cohorts that did not evaluate clinical outcomes, and 5) case reports.

\section{Literature Search and Selection}

A systematic search of the English-language literature from July 1990, to May 20, 2021, in the PubMed, Embase, and Cochrane databases was performed. The following medical subject heading terms and free text words were used: "ankylosing spondylitis" or "cervical fracture" or "surgical repair" or "anterior approach." A total of 130 published abstracts or manuscripts were identified. As illustrated in the PRISMA flowchart (Fig. 1), after applying the inclusion and exclusion criteria, a total of 7 articles were included in the qualitative analysis and 6 in the quantitative analysis. Selection and extraction of the studies were performed by two independent authors (V.G. and J.P.B.).

\section{Data Analysis}

The pooled data analysis was performed with Review Manager version 5.4 (The Cochrane Collaboration). Odds ratios and $95 \%$ confidence intervals were calculated with the Mantel-Haenszel test, and forest plots were generated for each comparison. Fixed-effects dichotomous models were developed to assess the overall effect of each approach in control and treatment groups. Our primary outcome was neurological improvement. Other secondary outcomes included complication rates. Risk of bias was assessed using the Cochrane risk-of-bias tool to give further insight into the conclusions made by the authors and our own subsequent meta-analyses.

\section{Results}

\section{Study Selection and Characteristics}

Seven articles met the inclusion criteria from an initial pool of 130 articles. ${ }^{14-20}$ All articles evaluated neurological improvement clinically. Six studies were included in the quantitative analysis. Key differences are summarized in Table 1. Six studies compared the anterior approach with both posterior and anterior-posterior approaches, while 1 study evaluated only an anterior approach. All studies measured neurological status both pre- and postoperatively. Our risk-of-bias summary is presented in Fig. 2.

\section{Approach Frequency}

Frequency analysis of each surgical approach revealed that anterior-posterior approaches were most common among our included studies, followed by anterior approaches, with posterior approaches being the least commonly employed surgical method. However, there were no significant differences between usage rates of an anterior approach versus those of posterior or anterior-posterior approaches $(\mathrm{p}=0.68$ and $\mathrm{p}=0.59$, respectively; Fig. 3 ).

\section{Anterior Versus Posterior Approaches}

Neurological improvement rates, in most studies, were reported as a change in preoperative and postoperative Frankel grades, with most studies presenting an overall proportion of patients who experienced some degree of neurological improvement. Our pooled analysis demonstrated no significant differences in overall rates of neurological improvement between anterior and posterior approaches, although anterior approaches trended toward lower rates of neurological improvement (OR 0.40,95\% CI $0.10-1.59 ; \mathrm{p}=0.19$ ) as shown in Fig. 4A. However, when comparing the mean change in postoperative neurological function, patients who underwent anterior approaches demonstrated a significantly lower mean neurological improvement as evidenced by the mean change in Frankel grade (MD $-0.60,95 \%$ CI -0.76 to $-0.45 ; \mathrm{p}<0.00001$ [Fig. 4B]). There were no significant differences in complication rates, though anterior approaches trended toward lower complication rates (OR $0.75,95 \%$ CI $0.22-2.54 ; \mathrm{p}=$ 0.65 [Fig. 4C]). 


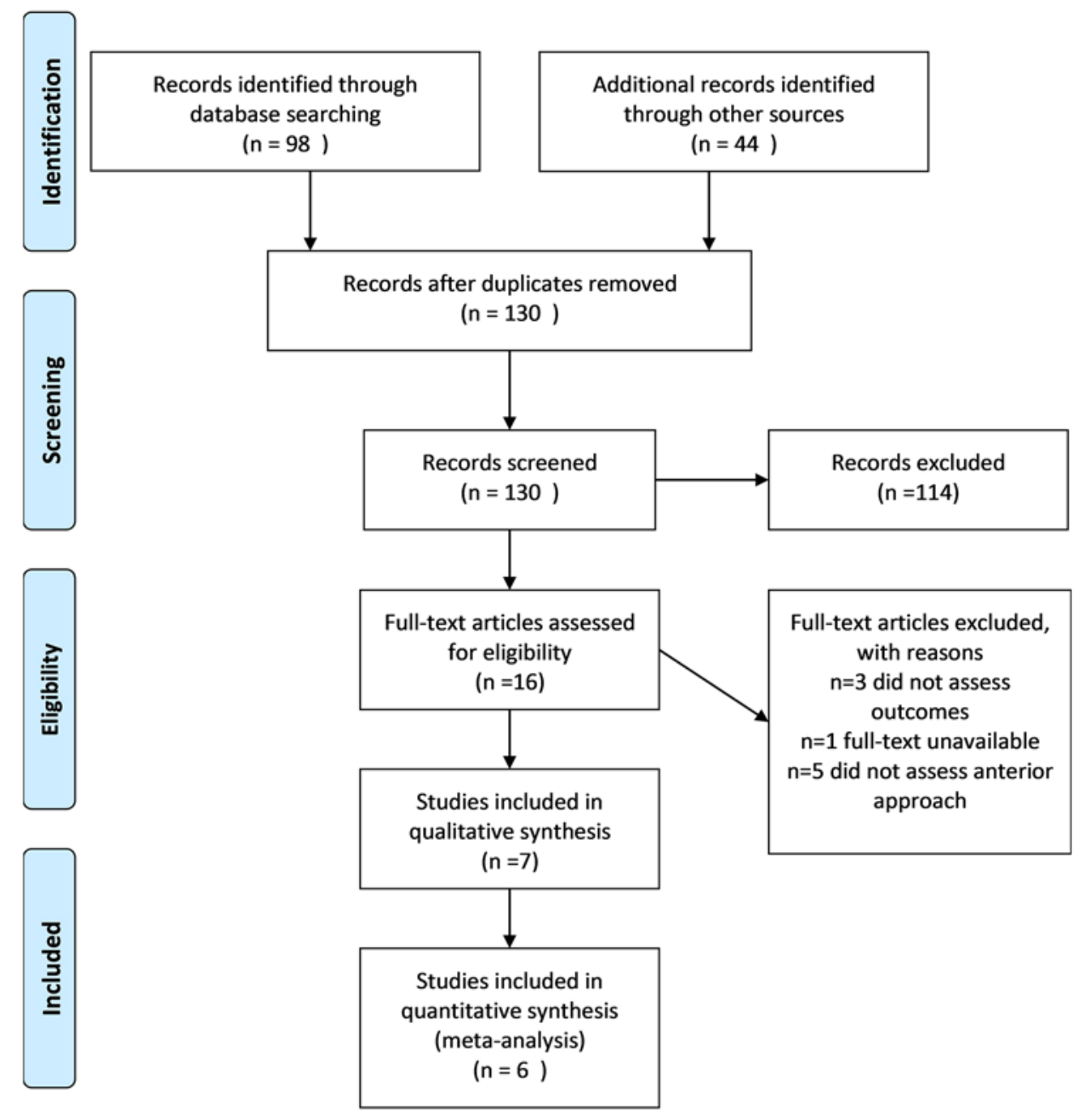

FIG. 1. PRISMA flow diagram of the study selection process.

\section{Anterior Versus Anterior-Posterior Approaches}

Our analysis of neurological outcomes and complication rates between anterior and anterior-posterior approaches revealed a trend similar to that of anterior versus posterior approaches. There were no significant differences between overall rates of neurological improvement, although patients who underwent anterior-posterior approaches trended toward higher rates of neurological improvement (OR 3.05, 95\% CI 0.84-11.15; $\mathrm{p}=0.09$ [Fig. $5 \mathrm{~A}]$ ). However, patients who underwent anterior approaches experienced a significantly lower mean change in postoperative neurological status (MD $-0.46,95 \%$ CI -0.60 to $-0.32 ; \mathrm{p}<0.00001$ [Fig. 5B]). Once again, there were no significant differences in complication rates between the two approaches, although anterior-posterior approaches trended toward higher complication rates (OR 1.52, 95\% CI 0.53-4.33; $\mathrm{p}=0.43$ [Fig. 5C]).

\section{Discussion}

The relative rarity of AS-associated cervical fractures has led to a lack of consensus regarding the optimal surgical technique for definitive treatment. Currently, ante- rior, posterior, and anterior-posterior fixation are the most commonly used surgical approaches; however, the current level of evidence regarding the utility of anterior approaches remains unclear.

All included studies evaluated neurological improvement in patients who underwent surgical management of AS-related cervical fractures. ${ }^{14-20}$ Although we were unable to detect significant differences in overall rates of neurological improvement, we found that patients who underwent anterior fixation demonstrated a significantly lower mean postoperative neurological improvement relative to patients who underwent posterior or anterior-posterior fixations, as evidenced by the mean change in preoperative (MD $-0.60,95 \% \mathrm{CI}-0.76$ to $-0.45 ; \mathrm{p}<0.00001$ ) and postoperative (MD $-0.46,95 \% \mathrm{CI}-0.60$ to $-0.32 ; \mathrm{p}<0.00001$ ) Frankel grades. These findings are corroborated by Longo et al., who previously reviewed the existing literature and also demonstrated that patients who underwent anterior fixation experienced worse neurological outcomes. ${ }^{13}$ An anterior surgical approach has been reported to be efficacious in patients with cervical fractures who also had spinal cord compression and mild dislocation and did not have severe osteoporosis and/or kyphosis. ${ }^{21}$ Furthermore, 
Govindarajan et al.

TABLE 1. Summary of included studies including primary endpoint, treatment, and follow-up

\begin{tabular}{|c|c|c|c|c|c|c|c|c|}
\hline $\begin{array}{l}\text { Authors } \\
\& \text { Year }\end{array}$ & $\begin{array}{l}\text { Study } \\
\text { Type }\end{array}$ & $\begin{array}{l}\text { No. of } \\
\text { Pts }\end{array}$ & $\begin{array}{c}\text { Mean } \\
\text { Age (yrs) }\end{array}$ & Procedure & Intervention & $\begin{array}{l}\text { Control } \\
\text { Arm }\end{array}$ & $\begin{array}{l}\text { Primary } \\
\text { Endpoint }\end{array}$ & $\begin{array}{c}\text { Mean FU } \\
\text { Duration (mos) }\end{array}$ \\
\hline $\begin{array}{l}\text { Ökten et al., } \\
2021^{19}\end{array}$ & Retrospective & 50 & 59.45 & $\begin{array}{l}\text { Anterior, posterior, or anterior- } \\
\text { posterior }\end{array}$ & $\begin{array}{l}\text { Anterior } \\
(n=7)\end{array}$ & $\begin{array}{l}\text { Posterior fixation ( } n= \\
\text { 18), anterior-posterior } \\
\text { fixation }(n=25)\end{array}$ & $\mathrm{NI}$ & 48 \\
\hline $\begin{array}{l}\text { Olerud et al., } \\
1996^{20}\end{array}$ & Retrospective & 19 & 60 & $\begin{array}{l}\text { Anterior or posterior fixation } \\
\text { w/ or w/o decompression }\end{array}$ & $\begin{array}{l}\text { Anterior } \\
\text { fixation } \\
(n=6)\end{array}$ & $\begin{array}{l}\text { Posterior fixation }(n=6) \text {, } \\
\text { anterior-posterior fixa- } \\
\text { tion }(n=6)\end{array}$ & $\mathrm{NI}$ & 27 \\
\hline $\begin{array}{l}\text { Einsiedel et } \\
\text { al., } 2006^{16}\end{array}$ & Retrospective & 36 & 65.3 & $\begin{array}{l}\text { Anterior-posterior, anterior } \\
\text { fixation, or posterior fixation }\end{array}$ & $\begin{array}{l}\text { Anterior } \\
(n=10)\end{array}$ & $\begin{array}{l}\text { Anterior-posterior }(n= \\
24), \text { posterior }(n=2)\end{array}$ & $\mathrm{NI}$ & Unknown \\
\hline $\begin{array}{l}\text { An et al., } \\
2014^{14}\end{array}$ & Retrospective & 9 & 55.2 & $\begin{array}{l}\text { Anterior, anterior-posterior, or } \\
\text { posterior fixation; others } \\
\text { underwent anterior discec- } \\
\text { tomy \& fusion }\end{array}$ & $\begin{array}{l}\text { Anterior } \\
(n=2)\end{array}$ & $\begin{array}{l}\text { Anterior-posterior }(n=1) \text {, } \\
\text { posterior }(n=3)\end{array}$ & $\mathrm{NI}$ & 43.4 \\
\hline $\begin{array}{l}\text { Badve et al., } \\
2010^{15}\end{array}$ & Retrospective & 6 & 46.13 & $\begin{array}{l}\text { Anterior, posterior, or anterior- } \\
\text { posterior }\end{array}$ & $\begin{array}{l}\text { Anterior } \\
(n=1)\end{array}$ & $\begin{array}{l}\text { Posterior }(n=4) \text {, anterior- } \\
\text { posterior }(n=1)\end{array}$ & $\mathrm{NI}$ & 54.5 \\
\hline $\begin{array}{l}\text { Kouyoumdjian } \\
\text { et al., } 2012^{18}\end{array}$ & Retrospective & 18 & 61 & $\begin{array}{l}\text { Anterior, posterior, or anterior- } \\
\text { posterior }\end{array}$ & $\begin{array}{l}\text { Anterior } \\
(n=16)\end{array}$ & $\begin{array}{l}\text { Posterior }(n=1) \text {, anterior- } \\
\quad \text { posterior }(n=1)\end{array}$ & $\mathrm{NI}$ & 45 \\
\hline $\begin{array}{l}\text { El-Salam et } \\
\text { al., } 2017^{17}\end{array}$ & Retrospective & 7 & 55.9 & Anterior & $\begin{array}{l}\text { Anterior } \\
(n=7)\end{array}$ & NA & $\mathrm{NI}$ & 24.5 \\
\hline
\end{tabular}

$\mathrm{FU}=$ follow-up; $\mathrm{NA}=$ not available; $\mathrm{NI}$ = neurological improvement; $\mathrm{pt}=$ patient.

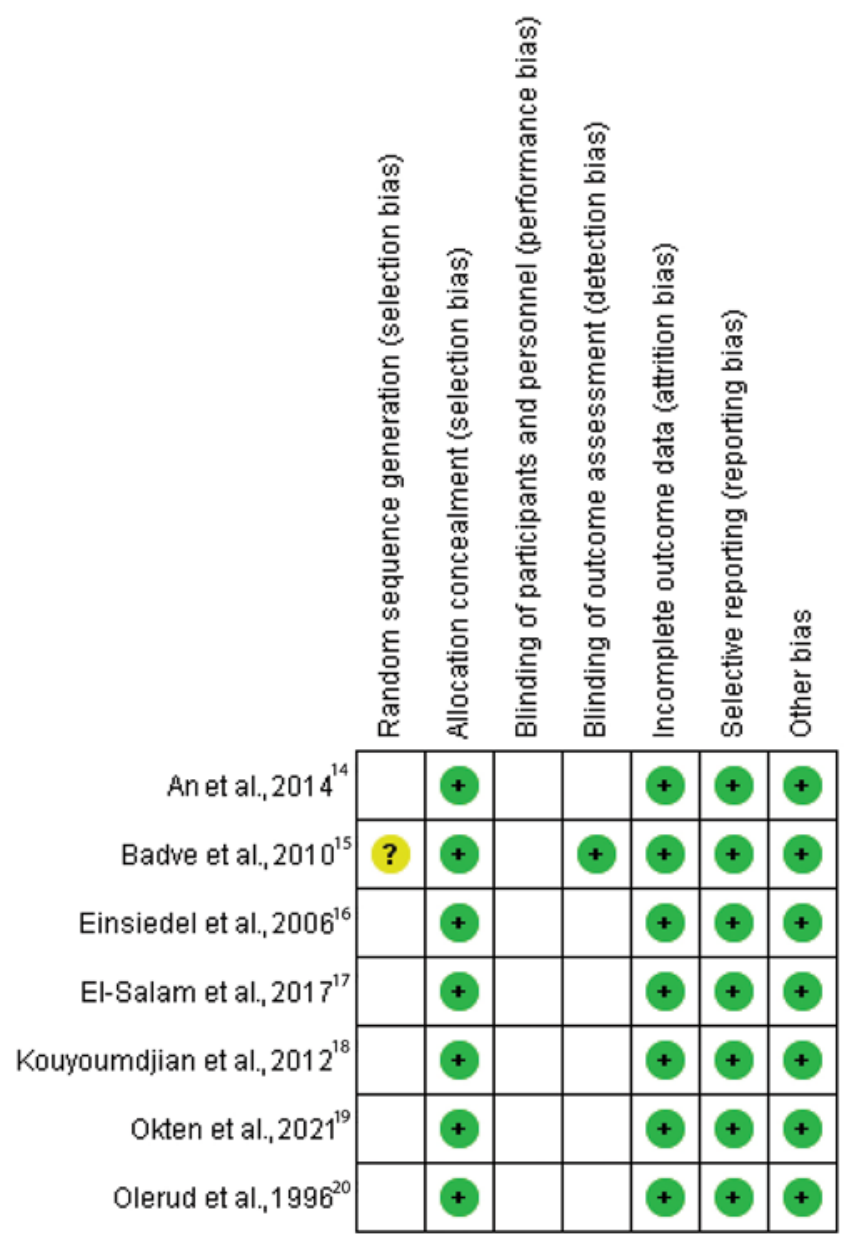

FIG. 2. Risk-of-bias summary. Green indicates low risk and yellow or blank unknown risk. patients exerting low levels of activity in the perioperative period were most amenable to treatment with an anterior surgical approach. ${ }^{21}$ Conversely, patients with severe cervical kyphosis and osteoporosis displayed poorer outcomes from an anterior approach due to difficulties in surgical exposure and subsequent fixation. ${ }^{21}$ In this case, substantial flexion stress at the fracture site can lead to instrumentation failure. Despite these obstacles, Guo et al. reported favorable results using a single anterior approach to treat

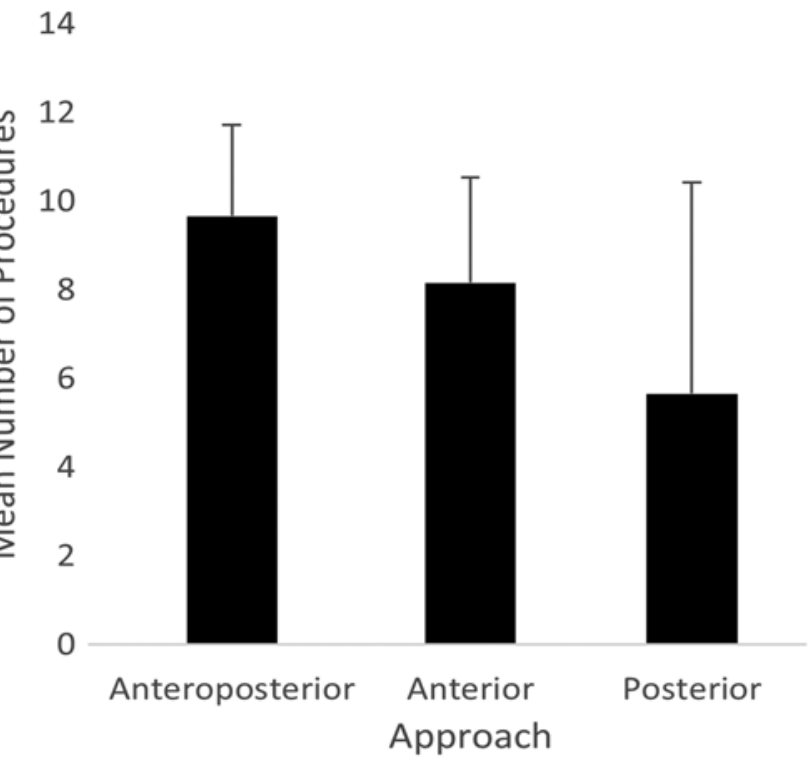

FIG. 3. The mean frequency of each investigated approach. There were no significant differences in the mean approach rate among our included studies. 


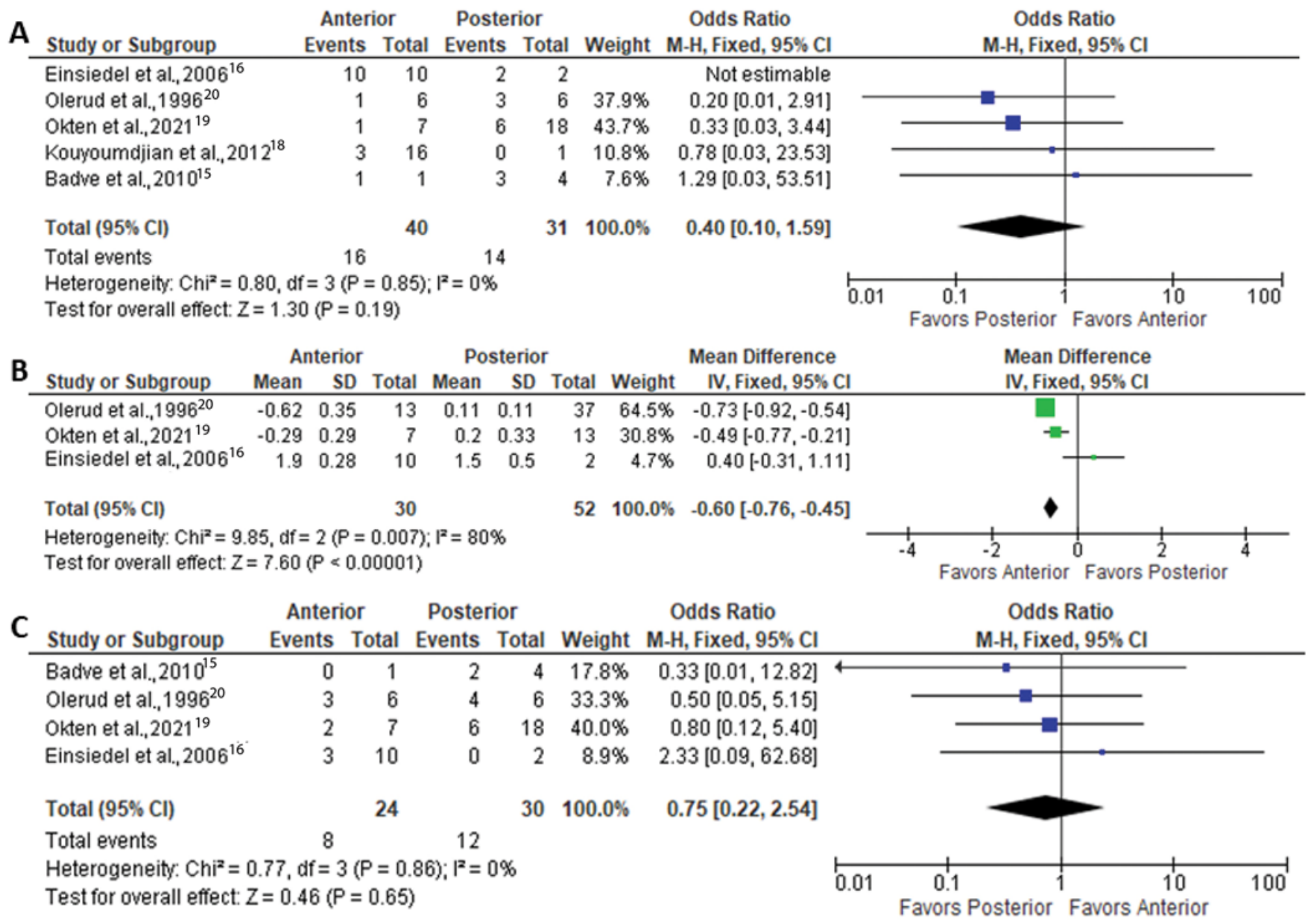

FIG. 4. Impact of surgical approach (anterior vs posterior) on rates of neurological improvement (A), mean change in postoperative neurological function $(\mathbf{B})$, and complication rates $(\mathbf{C})$. There were no significant differences in overall rates of neurological improvement between anterior and posterior approaches (OR 0.40, 95\% $\mathrm{Cl} 0.10-1.59 ; p=0.19$ ). However, patients who underwent anterior approaches experienced a significantly lower mean change in postoperative neurological function (MD $-0.60,95 \% \mathrm{Cl}$ -0.76 to $-0.45 ; p<0.00001)$. There were no significant differences in the complication rates between anterior and posterior approaches $(\mathrm{OR} 0.75,95 \% \mathrm{Cl} 0.22-2.54 ; \mathrm{p}=0.65)$. IV = inverse variance; $\mathrm{M}-\mathrm{H}=$ Mantel-Haenszel test.

cervical spinal fractures in patients with AS. ${ }^{21}$ Ninety percent of their cohort (9 of 10) who underwent anterior-only surgery with subsequent postoperative cervical immobilization achieved successful bone fusion, and none demonstrated signs of instrumentation failure. The authors attributed their successful outcomes to enhancement of the anterior fixation before fusion by postoperative cervical immobilization, immediate stability provided by anterior fixation, and a low level of activity in $70 \%$ of their patients, which decreased downward force on the construct.

Regarding postoperative complication rates, we found no significant differences between anterior fixation and other investigated approaches. Complications which have been associated with an anterior surgical approach include dysphagia, hoarseness, respiratory issues, nonunion, and graft subsidence. ${ }^{21}$ Additionally, pulmonary complications such as respiratory failure and iatrogenic pneumothorax have been associated with anterior fixation. ${ }^{22}$ However, in our study, we observed that an anterior approach trended toward lower overall complication rates. This finding is contrary to previous research that found that patients who underwent anterior fixation experienced higher rates of instrumentation failure requiring revision surgery, as noted by Longo et al. ${ }^{13,23,24}$ One National (Nationwide) Inpatient Sample (NIS) study revealed that patients who underwent anterior-posterior approaches had an extended hospital length of stay and higher rates of pulmonary complications. ${ }^{22}$ This may be related to surgeon bias in utilizing circumferential fixation in patients with worse fractures. The cause of this discrepancy is unclear but may be elucidated with larger-scale studies.

The results of our pooled analyses reveal a general trend: while anterior approaches may offer less favorable neurological improvement relative to posterior or anteriorposterior approaches, they may translate to lower complication rates. One potential explanation for this finding is that patients who underwent anterior approaches may have had higher preoperative neurological function, thus mitigating the potential degree of improvement. However, Longo et al. did not find significant differences in preop- 


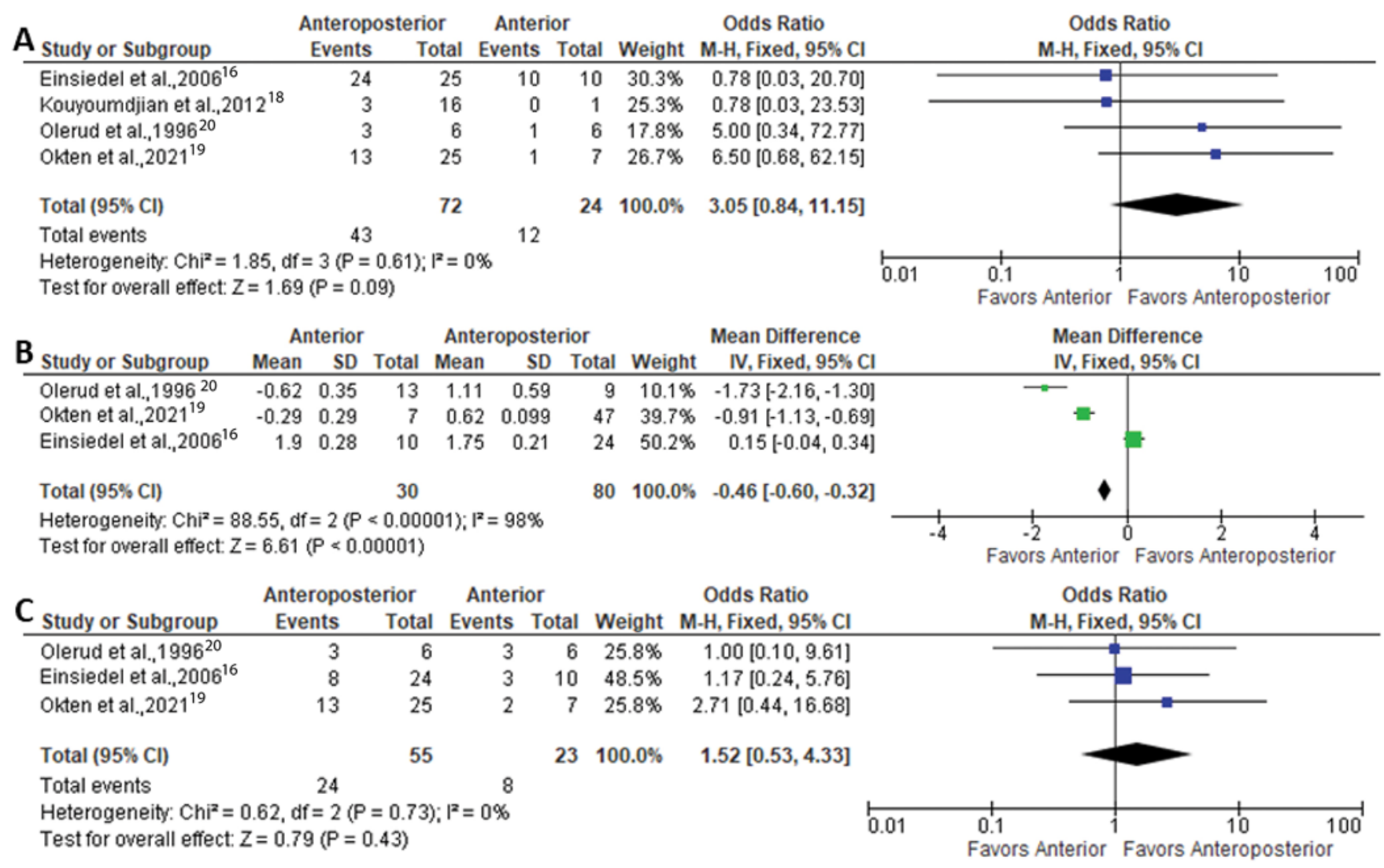

FIG. 5. Impact of surgical approach (anterior vs posterior) on rates of neurological improvement (A), mean change in postoperative neurological function (B), and complication rates (C). There were no significant differences in rates of neurological improvement between patients who underwent anterior and anterior-posterior approaches (OR 3.05, 95\% Cl 0.84-11.15; $p=0.09$ ). However, patients who underwent anterior approaches experienced a significantly lower mean change in postoperative neurological function $(\mathrm{MD}-0.46,95 \% \mathrm{Cl}-0.60$ to $-0.32 ; \mathrm{p}<0.00001)$. There were no significant differences in complication rates between anterior and anterior-posterior approaches (OR 1.52, 95\% Cl 0.53-4.33; $p=0.43$ ).

erative Frankel grades across their investigated studies. ${ }^{1}$ Thus, surgical technique should be selected based on patient characteristics such as the degree of neurological impairment, overall morbidity profile, fracture severity, and suspected postoperative physical activity. The aforementioned studies have indicated that anterior approaches may be more appropriate in healthier individuals or individuals with limited mobility. Future studies should also analyze potential differences in preoperative neurological status to determine whether it impacts the mean postoperative change in neurological status.

\section{Limitations}

The primary limitation of our study was a lack of clinical trials investigating various approaches to surgical treatment of AS-related cervical fractures. The paucity of data on this topic is most likely a result of the relative rarity of these fractures, which has forced researchers to rely on retrospective formats to produce sufficiently large cohorts. While some studies have previously relied on the NIS to produce large data sets, the utility of NIS-based samples has been called into question, mainly as a product of their tendency to treat readmissions as separate cases, thus artificially inflating differences..$^{25}$ Furthermore, even among the included articles, authors tended not to provide objective metrics regarding clinical outcomes aside from neurological improvement and complication rates.

\section{Conclusions}

Our systematic review and meta-analysis demonstrate the differential benefits of anterior, posterior, and anteriorposterior approaches in treatment of cervical fractures associated with AS. We have demonstrated that while anterior approaches may be associated with lower degrees of neurological improvement, they may be less likely to result in postoperative complications. However, larger studies are required to elucidate the utility of these approaches, particularly studies that investigate long-term clinical outcomes or other objective patient outcomes.

\section{References}

1. Braun J, Sieper J. Ankylosing spondylitis. Lancet. 2007; 369(9570):1379-1390.

2. Mori K, Ushiyama T, Inoue K, Hukuda S. Polymorphic $\mathrm{CAG}$ repeats of the androgen receptor gene in Japanese male patients with ankylosing spondylitis. Rheumatology (Oxford). 2000;39(5):530-532. 
3. Woodward LJ, Kam PC. Ankylosing spondylitis: recent developments and anaesthetic implications. Anaesthesia. 2009; 64(5):540-548.

4. Hartmann S, Tschugg A, Wipplinger C, Thomé C. Analysis of the literature on cervical spine fractures in ankylosing spinal disorders. Global Spine J. 2017;7(5):469-481.

5. El Maghraoui A, Bensabbah R, Bahiri R, Bezza A, Guedira N, Hajjaj-Hassouni N. Cervical spine involvement in ankylosing spondylitis. Clin Rheumatol. 2003;22(2):94-98.

6. Yilmaz N, Pence S, Kepekçi Y, Geyikli I, Ozaslan J. Association of immune function with bone mineral density and biochemical markers of bone turnover in patients with anklylosing spondylitis. Int J Clin Pract. 2003;57(8):681-685.

7. El Maghraoui A. Osteoporosis and ankylosing spondylitis. Joint Bone Spine. 2004;71(4):291-295.

8. Mac Millan M, Stauffer ES. Traumatic instability in the previously fused cervical spine. J Spinal Disord. 1991;4(4): 449-454.

9. Lukasiewicz AM, Bohl DD, Varthi AG, Basques BA, Webb ML, Samuel AM, Grauer JN. Spinal fracture in patients with ankylosing spondylitis: cohort definition, distribution of injuries, and hospital outcomes. Spine (Phila Pa 1976). 2016; 41(3):191-196.

10. Whang PG, Goldberg G, Lawrence JP, Hong J, Harrop JS, Anderson DG, et al. The management of spinal injuries in patients with ankylosing spondylitis or diffuse idiopathic skeletal hyperostosis: a comparison of treatment methods and clinical outcomes. J Spinal Disord Tech . 2009;22(2):77-85.

11. Jacobs WB, Fehlings MG. Ankylosing spondylitis and spinal cord injury: origin, incidence, management, and avoidance. Neurosurg Focus. 2008;24(1):E12.

12. Lazennec JY, d'Astorg H, Rousseau MA. Cervical spine surgery in ankylosing spondylitis: review and current concept. Orthop Traumatol Surg Res. 2015;101(4):507-513.

13. Longo UG, Loppini M, Petrillo S, Berton A, Maffulli N, Denaro V. Management of cervical fractures in ankylosing spondylitis: anterior, posterior or combined approach? $\mathrm{Br}$ Med Bull. 2015;115(1):57-66.

14. An SB, Kim KN, Chin DK, Kim KS, Cho YE, Kuh SU. Surgical outcomes after traumatic vertebral fractures in patients with ankylosing spondylitis. J Korean Neurosurg Soc. 2014; 56(2):108-113.

15. Badve SA, Bhojraj SY, Nene AM, Varma R, Mohite S, Kalkotwar S, Gupta A. Spinal instability in ankylosing spondylitis. Indian J Orthop. 2010;44(3):270-276.

16. Einsiedel T, Schmelz A, Arand M, Wilke HJ, Gebhard F, Hartwig E, et al. Injuries of the cervical spine in patients with ankylosing spondylitis: experience at two trauma centers. $J$ Neurosurg Spine. 2006;5(1):33-45.

17. El-Salam Wafa MA, Ibrahim FMF, Ibrahim MZ. Surgical treatment of vertebral fractures in patients with ankylosing spondylitis: a retrospective study. Curr Orthop Pract. 2017; 28(4):424-429.
18. Kouyoumdjian P, Guerin P, Schaelderle C, Asencio G, Gille $\mathrm{O}$. Fracture of the lower cervical spine in patients with ankylosing spondylitis: retrospective study of 19 cases. Orthop Traumatol Surg Res. 2012;98(5):543-551.

19. Ökten AI, Arslan A, Iştemen İ, et al. Surgical outcomes of subaxial cervical fractures in patients with ankylosing spinal disorder. Turk Neurosurg. 2021;31(4):510-518.

20. Olerud C, Frost A, Bring J. Spinal fractures in patients with ankylosing spondylitis. Eur Spine J. 1996;5(1):51-55.

21. Guo Q, Cui Y, Wang L, Lu X, Ni B. Single anterior approach for cervical spine fractures at C5-T1 complicating ankylosing spondylitis. Clin Neurol Neurosurg. 2016;147:1-5.

22. Kurucan E, Bernstein DN, Mesfin A. Surgical management of spinal fractures in ankylosing spondylitis. J Spine Surg. 2018;4(3):501-508.

23. Cooper PR, Cohen A, Rosiello A, Koslow M. Posterior stabilization of cervical spine fractures and subluxations using plates and screws. Neurosurgery. 1988;23(3):300-306.

24. Exner G, Bötel U, Kluger P, Richter M, Eggers C, Ruidisch M. Treatment of fracture and complication of cervical spine with ankylosing spondylitis. Spinal Cord. 1998;36(6):377379.

25. Khera R, Krumholz HM. With great power comes great responsibility: big data research from the National Inpatient Sample. Circ Cardiovasc Qual Outcomes. 2017;10(7): e003846.

\section{Disclosures}

Dr. Wang receives royalty payments from DePuy Synthes Spine, Inc., Children's Hospital of Los Angeles, Springer Publishing, and Quality Medical Publishing; is a consultant for DePuy Synthes Spine, Inc., Stryker Spine, K2M, Medtronic, and Spineology; is an advisory board member for Vallum; has direct stock ownership in Spinicity, Innovative Surgical Devices, Medical Device Partners, and Kinesiometrics; and receives grants from the Department of Defense.

\section{Author Contributions}

Conception and design: Wang, Perez-Roman. Acquisition of data: Govindarajan, Bryant. Analysis and interpretation of data: Govindarajan, Bryant. Drafting the article: Govindarajan, Bryant. Critically revising the article: Wang, Perez-Roman. Reviewed submitted version of manuscript: Govindarajan, Perez-Roman. Statistical analysis: Govindarajan. Study supervision: PerezRoman.

\section{Correspondence}

Michael Y. Wang: University of Miami Miller School of Medicine, Miami, FL. mwang2@med.miami.edu. 